\title{
From the Observable to the Explorable: Investigating Creative Research in Design as a Means for Guiding Critical Action
}

\author{
BROOKE CHORNYAK ${ }^{1}$ AND TANIA ALLEN ${ }^{2}$ \\ 1. Northeastern University, Boston, MA, USA. \\ 2. North Carolina State University, College of Design, Raleigh, NC, USA
}

\author{
SUGGESTED CITATION: Chornyak, B. \& Allen, T. "From the Observable to the Explorable: Investigating Creative Research in Design as a \\ Means for Guiding Critical Action.” Dialectic, 3.1 (2021): pgs. 58-83. \\ Published by the AIGA Design Educators Community (DEC) and Michigan Publishing. \\ DOI: http://doi.org/10.3998/dialectic.14932326.0003.103 \\ STABLE URL: http://hdl.handle.net/2027/spo.14932326.0003.103
}

\section{Abstract}

As design and design research continues to evolve to address increasingly systemic and complex problems, the language of what designers "do" similarly evolves along a spectrum from problemsolving to sense-making. ${ }^{1}$ An opportunity also exists within this dialogue to consider new forms of hybrid research methods that complement and support design as an independent domain of knowledge. Creative research - commonly used in the fine arts and humanities to examine how a given individual's or group's use of original ideas or imagination guides the operation of specific methods and offers key insights for gathering a type of data that has wide-ranging advantages in design research. It also provides techniques and perspectives that designers might integrate and build upon as they interrogate various aspects of their decision-making processes-especially as they attempt to dismantle preconceptions and biases regarding findings. By critically assessing a series of case studies, this paper will explore the following questions:

- How can creative research help designers identify and formulate critical questions that challenge their own assumptions about what is informing their recommendations for preferred conditions for intervention?

- In what ways can the act of play - creating joyful, low-stakes situations where ideas can be tested in open-ended environments - operate as a condition for creative research to succeed? 
- How might creative research be used to effectively practice deeper empathy on behalf of those affected by design decision-making that moves beyond the physical and into the messier areas of cognitive, emotional and even philosophical worldviews as part of the participatory and co-design process?

1 Kolko, J. "Sensemaking and Framing: A Theoretical Reflection on Perspective in Design Synthesis" in Proceedings of the Design Research Society Conference, 7-9 July 2010, Montreal, Quebec, Canada, edited by Durling, D., Bousbaci, R., Chen, L.L., Gauthier, P., Poldma,

T., Roworth-Stokes, S. \& Stolterman, E. Montreal, Quebec, Canada. Online. Available at: http://www.jonkolko.com/ writingSensemaking.php (Accessed July 23, 2021). 


\section{From the Observable to the Explorable:}

Investigating Creative Research in Design as a Means for

Guiding Critical Action

BROOKE CHORNYAK \& TANIA ALLEN

2

Poggenpohl, S. "Time for Change: Building a Design Discipline." In

Design Integrations: Research

and Collaboration. Edited by S. Poggenpohl and K. Sato, pgs. 3-22. Bristol, UK: Intellect Ltd, 2009.

\section{3}

Buchanan, R. "Wicked Problems in

Design Thinking." In The Idea of Design. Edited by R. Buchanan and V. Margolin, pgs. 3-20. Cambridge, MA, USA: The MIT Press, 1996.

\section{4}

Cross, N. "Designerly Ways of Knowing: Design Discipline versus Design Science." Design Issues, 17.3 (2001): pgs. 49-55.

\section{5}

Cross, N. Designerly Ways of Knowing. New York, NY, USA:

Springer, 2006.

6

Simon, H. The Sciences of the Artificial, Third Edition. Cambridge, MA, USA: The MIT Press, 1970.

\section{Introduction}

There are three basic, interrelated factors we see that contribute to the current state of design research in general, and the relationship between design research and creative research more specifically. The first is the attempt to differentiate design from art, and the language and categories that have emerged as a result. The second is the move to establish design as a discipline-distinguishing it from its craft origins and more closely aligning it with the sciences, both physical and social. ${ }^{2,3,4}$ The third is the establishment of design thinking as an intellectual process that can yield new knowledge and understandings with distinct characteristics that are more or less repeatable. ${ }^{5}$

In part, these factors have contributed to design research rooted in empirical studies and scientific research, aimed at finding "universal truths" that are more or less repeatable from context to context, and which often assume universal preferences among what might be very different audiences and participants. ${ }^{6}$ Research methods often embraced in design — usability studies, user-centered research — attempt to create controlled environments and isolate a single aspect of interaction that can be studied more closely to reach this universality. Even the anonymity of the term "user" indicates a de-personalization that suggests a singular experience. As design processes evolved during the twentieth century, they shifted away from a paradigm centering on the kinds of universal outcomes realized during modernism (and, to 
some extent, during postmodernism, as many established, modernist design principles were questioned and often rejected). These types of design processes then gave way to those that sought to cultivate socially, politically and economically rich understandings of how and why specific groups of people think and behave as they do. This was and can still be seen in design movements such as transition design, participatory design and co-creative design. These developments in the evolution of design processes suggest that the ways designers plan and practice research need a similar examination, and may derive strong benefits from being open to embracing the ambiguity and messiness often necessary to analyze and understand the real-world contextual factors that affect and inform complex human experiences.

Acknowledging this shift in what design processes can be informed by forces a reconsideration of the methods that designers use to engage in the decision-making approaches and the methods that guide their work. Participatory and co-creative design move in this direction, but often do so by employing tightly framed ideological constraints and tools, which tend to provide a limited number of means for people who may be affected by given design endeavors to contribute their knowledge and understandings to the research process. ${ }^{7}$ Additionally, restricting design processes from being able to account for real-world contextual factors limits opportunities to challenge underlying assumptions - among both designers and those who will be affected by what is designed-about whether or not what is being proposed will, in fact, be preferred. Working this way can also limit questions about who has access to the power necessary to make crucial decisions. Investigating alternative research paradigms that are rooted in disciplines focused on socially and culturally rooted interpretation and meaning could help designers glean key insights about the assumptions, perceptions and motivations of those for and with whom they are designing, and shift the focus of their research towards a process guided by person-focused, idiosyncratically informed discovery.

Creative research is most commonly practiced in the fine arts and humanities, where the means of creative production is a core component of the research process. Much like Christopher Frayling's characterization of research through design, ${ }^{8}$ creative research uses the activity of making something as a way to unpack or examine the activity itself, and the various contextual factors - socio-cultural, ethical, values-based, etc. - that inform it. Creative research is often characterized as a means to use creative methods within other, larger research paradigms to produce or realize understandings 


\section{9 \\ Kara, H. Creative Research Methods in the Social Sciences, A Practical Guide, pg 3. Bristol, UK: Policy Press, 2015.

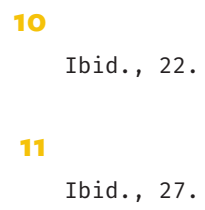

that inform how and why people engage in given methods or processes. For example, using poetic analyses in a phenomenological study might provide a means to engage participants more openly and contribute to a better understanding of why they perceive particular experiences as they do. We think these kinds of approaches have the potential to be incredibly useful to designers, but are also interested in whether there are elements of creative research that are inherent to the act of creativity itself that might provide a foundation for the advancement of a unique research method in and of itself-one that can operate beyond the symbolic activity of being creative (often synonymous with innovative), or that simply uses visual arts and design-based methods (painting, drawing, creative writing, model-making) to engage participants.

Helen Kara, author of Creative Research in the Social Sciences, suggests that there are four key frameworks that operate within creative research: artsbased, research using technology, mixed methods, and transformative. She contends that these are "not mutually exclusive... mixed methods research may be practiced within a transformative framework... transformative research may also be arts-based." 9 As Kara explains it, arts-based research, or research through creative practice, emphasizes qualities such as, "play, intuition, serendipity, imagination, and the unexpected as resources for making sense." ${ }^{10}$ Mixed methods research "involves combining different methods of data gathering and/or analysis, different types of recruitment or sampling, different theoretical and/or disciplinary perspectives, and so on. It is often considered particularly useful for investigating complex social situations." ${ }^{11}$ Research using computerized, digital technologies provides opportunities for disseminating communications among and accessing more diverse constituencies of participants, and affords opportunities to access communities that might exist solely online. Additionally, using online platforms to augment physical interactions can provide researchers with data that they could not otherwise obtain. Finally, transformative frameworks are "based on, and intended to promote, positive social values such as equality and justice." ${ }^{12}$ Transformative frameworks are meant to be flexible and adaptive, and respond more easily to changing conditions, contexts and situations. Through transformative frameworks, the knowledge between researcher and participant can also change and evolve with both being transformed as a result of the research process. These dimensions contribute a particularly useful and usable application for design research where the ultimate goal, in and of itself, is transformative. 


\section{3}

Dunne, A. and Raby, F. Speculative Everything: Design, Fiction, and Social Dreaming. Cambridge, MA, USA: The MIT Press, 2013.

\section{4}

Smyth, Michael. "The radical design movement, More essential history for Speculative Design" SpeculativeEdu (blog). Available at: https://speculativeedu.eu/ the-radical-design-movement/ (Accessed 26 July 2021).

\section{5}

Dunne, A. and Raby, F. Speculative Everything, 2013.

16

Manzini, E. Design, When Everybody Designs: An Introduction to Design for Social Innovation.

Cambridge, MA, USA, 2015.

\section{7}

"Social Justice Artist, Practitioner of Interrogative Design And Harvard University Professor Krzysztof Wodiczko,"

interview by Nancy Nesvet, Artscope. March 02, 2017. Available at: https://artscopemagazine. com/2017/03/social-justice-artist-practitioner-of-interrogativedesign-and-harvard-universityprofessor-krzysztof-wodiczko/ (Accessed 26 July 2021).

18

Sanders, Elizabeth B.-N, and Pieter Jan Stappers. Convivial Toolbox: Generative Research for the Front End of Design. Amsterdam: BIS Publishers, 2018.

19

Ratto, M. "OPEN DESIGN NOW." Open Design Now, Online. Available at: opendesignnow.org/index.php/article/critical-making-matt-ratto/. (Accessed 3 April 2021).
Critical design

Critical Design uses a variety of conceptual and speculative methods to raise critical questions about cultural, technical, physical, political and other societal issues and "challenge narrow assumptions, preconceptions, and givens about the role products play in everyday life." 13
Launched by art and design students in Florence, Italy in 1966 as a means to argue against the socio-economic and political establishment of the time, radical design evolved into a rejection of the design norms espoused by modernist design. The movement brought together dynamic and avant-garde thinkers and makers in design and the visual arts and lasted until $1977 .{ }^{14}$

\section{Speculative design or design fiction}

Interrogative design

Co-creation or co-design
Speculative design uses discursive design proposals to mediate and debate crucial issues that might happen in the future. Well known through the work of Anthony Dunne and Fiona Raby and their book Speculative Everything, it employs elements of science fiction, future casting and future scenarios "to open up all sorts of possibilities that can be discussed, debated, and used to collectively define a preferable future for a given group of people." 15

Italian design scholar Ezio Manzini asserts that everybody is endowed with the ability to design, though not with the same goals or attributes of professional designers. In diffuse design, the role of expert designers should be to create the conditions by which different social actors can take part in design processes in a more expert fashion. ${ }^{16}$

A community-based, co-design practice established by artist and professor Krzysztof Wodiczko, interrogative design raises questions about the complexity of today's world with the impetus to change perspectives and hopefully, future actions. ${ }^{17}$

Co-design is a design-led participatory process with an approach that actively attempts to involve all stakeholders to help ensure the results are not only usable but desirable. ${ }^{13}$
Critical making

We also acknowledge that there are a number of contemporary design research approaches that creative research has the potential to encapsulate. These include critical design — an umbrella term that includes historic
The convergence of critical thinking with making as a pedagogical practice, in critical making students engage with materials and technologies to open up and extend critical social reflection. Coined by professor Matt Ratto, it reconnects two modes of engagement with the world that are "typically held separate: critical thinking, traditionally understood as conceptually and linguistically based, and physical 'making', goal-based material work." 19 
practitioners from Italian radical design — as well as speculative design or design fiction. We would also include other practices like diffuse design, interrogative design, co-creation or co-design, and the emerging method that has come to be called critical making.

Within this landscape and looking at creative research writ large, there are a number of questions this paper seeks to unpack - specifically for the development of a systematic approach to incorporating creative methods into the design research process. These are articulated as follows:

- How can creative research help designers identify and formulate critical questions that challenge their own assumptions about what is informing their recommendations for preferred conditions for intervention?

- In what ways can the act of play_creating joyful, freeing situations and open-ended environments - be a condition for creative research to succeed?

- How might creative research be used to truly practice deeper empathy that moves beyond the physical and into the messier areas of cognitive, emotional and even philosophical worldviews as part of the participatory and co-design process?

By critically analyzing a series of three case studies that highlight different approaches to creativity and research, we will attempt to extract specific aspects of creative research that might help us set up conditions for effective, useful and innovative research findings - to "make the strange familiar and the familiar strange" - a saying attributed to both Ts Eliot (about "all good poetry") and Margaret Mead (about the goals of anthropology). ${ }^{20}$

\section{Raising Questions About Assumptions: Employing Visualization as a Critical Research Tool.}

To address the first of the three questions raised above, the first case study emerges from a research seminar for graduate students enrolled in design curricula at North Carolina State University that was led by one of the authors. The seminar explored the ways that techniques of data visualization could be used to depict emerging patterns and gaps in individual students' own research processes. Using a bibliography compiled from their initial literature review as "data," students engaged in a mixed methods and iterative approach 

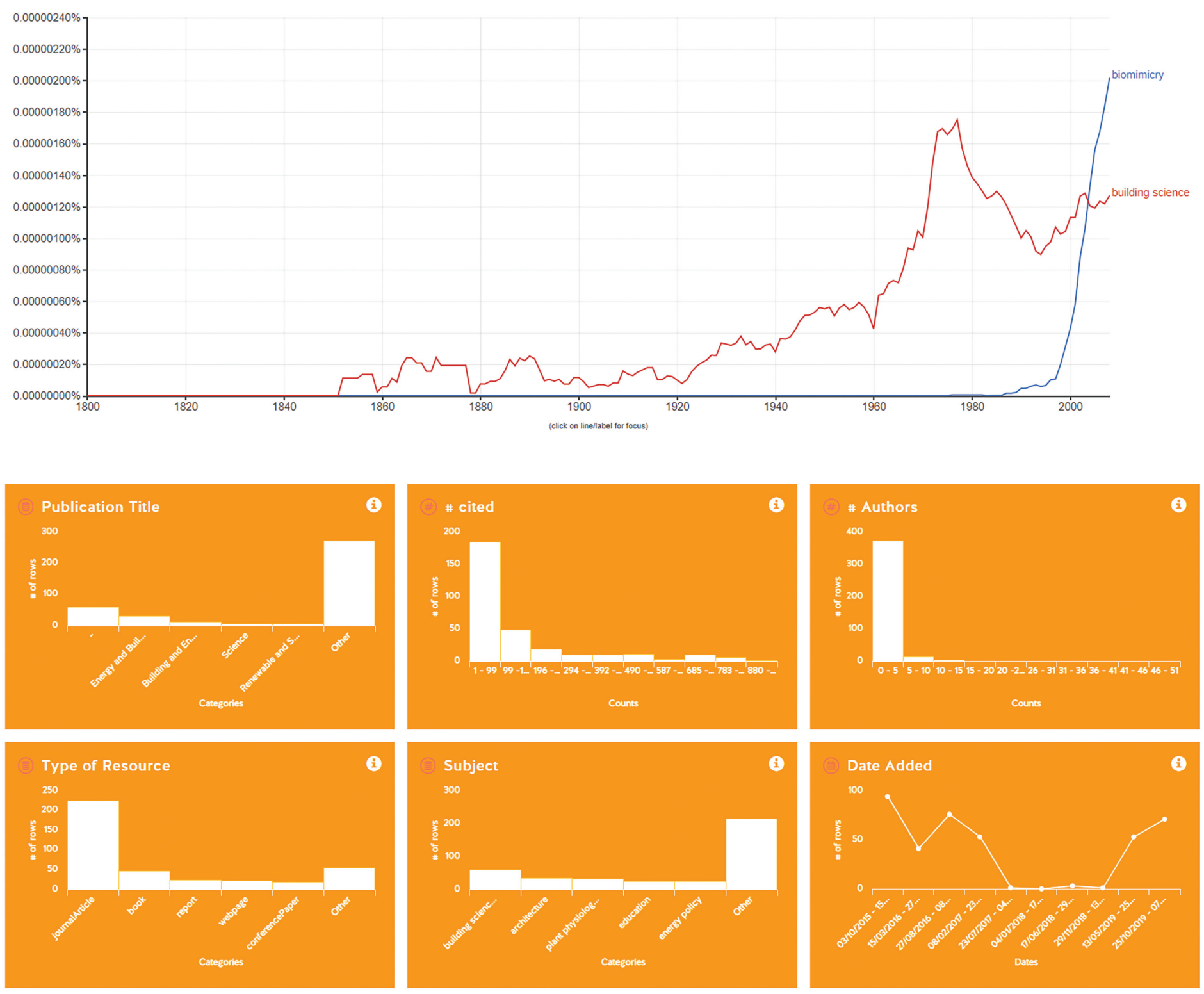

FIGURES 1-2: Example of preliminary visualizations from Google NGram (top) and Databasic.io (bottom) by Liz McCormick. Image Credit: Liz McCormick, North Carolina State University.

to visualizing the citations each of them included in this work to uncover hidden patterns and make meaning between seemingly unconnected pieces of information.

A key problem in formulating and operating design research (and many other types of research) can be the inclination to confirm assumptions held by the researchers at the risk of overlooking fundamental, surprising and unforeseen outcomes. Creativity, hereby defined as the act of creating, offers a keen opportunity for visual thinking, and examining patterns through the 


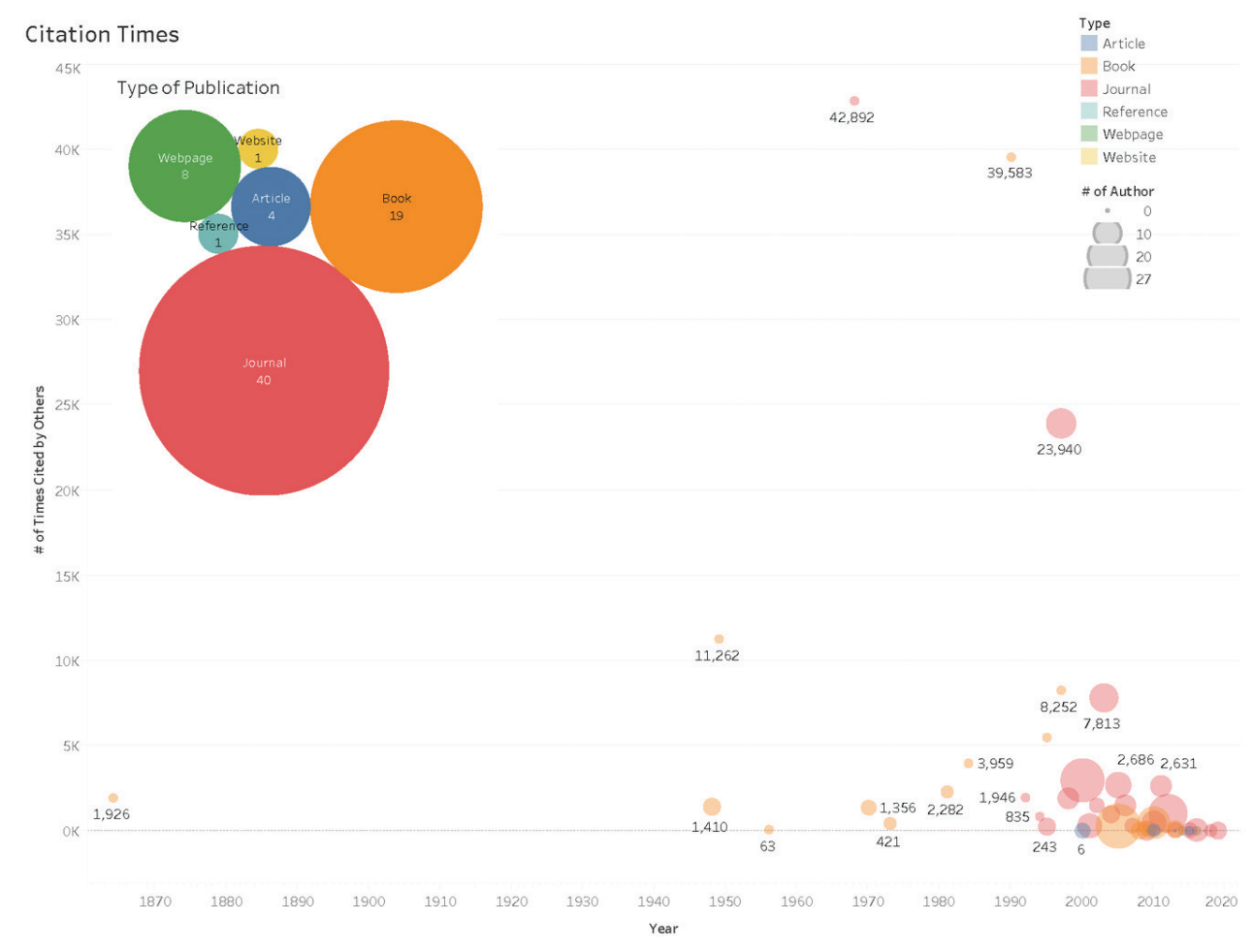

FIGURE 3: First example of iterative visualizations of citations and word count by Kelly Wang. Image Credit: Kelly Wang, North Carolina State University.

activity of interpretation and externalization. In other words, translating from the abstract to the concrete, or from the concrete to the abstract, forces an explicit wrestling with the information being communicated while also offering a tangible and observable artifact that can be challenged and interrogated.

Centering visualization and translation as tools for critical inquiry, the course was broken up into three distinct parts: visualizing the existing literature to discern emergent patterns, visualizing data implied but not explicitly included, and finally visualizing correlational information. Initially, students created a series of visualizations that looked at different dimensions of the "raw" data set-author(s) names, titles of work, keywords, year published, publisher - using Google NGram and Databasic.io. Google NGram depicts the frequency of certain keywords and terms calculated from the millions of texts archived in Google Books. Databasic.io is a platform created by Catherine D’Ignazio and Rahul Bhargava that allows users to quickly explore different dimensions of data. The aim of this stage was to encourage students to read the visualizations presented in each of these platforms, and then to discuss what was obvious and what was surprising to them. For example, the 


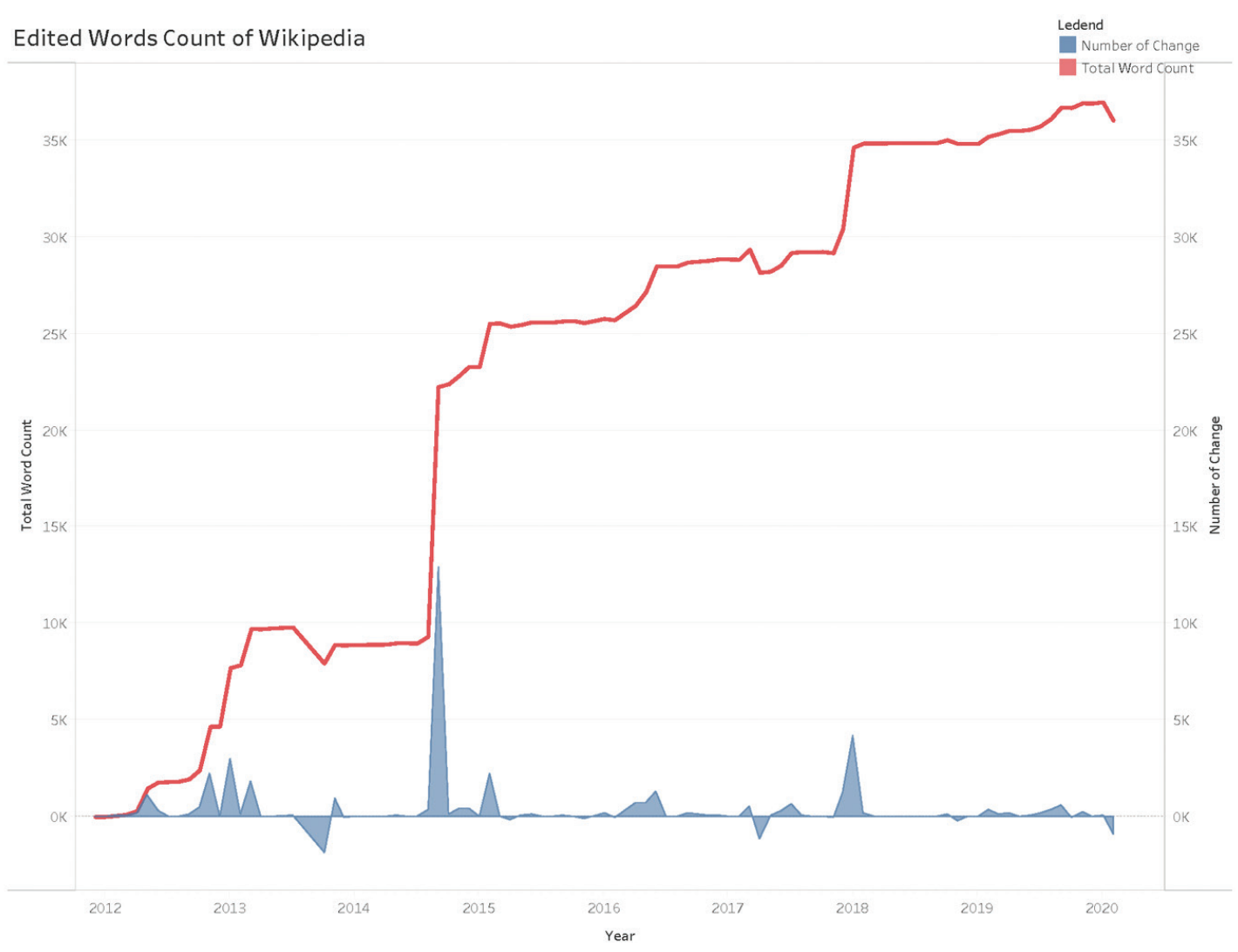

FIGURE 4: Second example of iterative visualizations of citations and word count by Kelly Wang. Image Credit: Kelly Wang, North Carolina State University.

visualization of word clouds that emerged from using these tools was least surprising in terms of what it revealed about language, but the year of the publication often revealed a density of articles from a certain era-which may or may not have been anticipated. It served as a starting point for deciding what additional information might need to be added or translated.

In phase two, students added two pieces of additional information, such as the gender of the first author, country of origin of the first author, the number of Google Scholar citations, or when the citation was added. Using additional tools such as Rawgraphs.io and Tableau, students then visualized different dimensions of their data sets in a number of ways - temporally, spatially and as networks. Students were encouraged to actively interrogate the assumptions they had been making about their research, including authorship, perspective and credibility. It also provided an opportunity to talk specifically about the way that the visualization added meaning or skewed interpretations. In breaking apart the data to look at each piece independently and then re-assembling or reintegrating it, students reflected on how their 

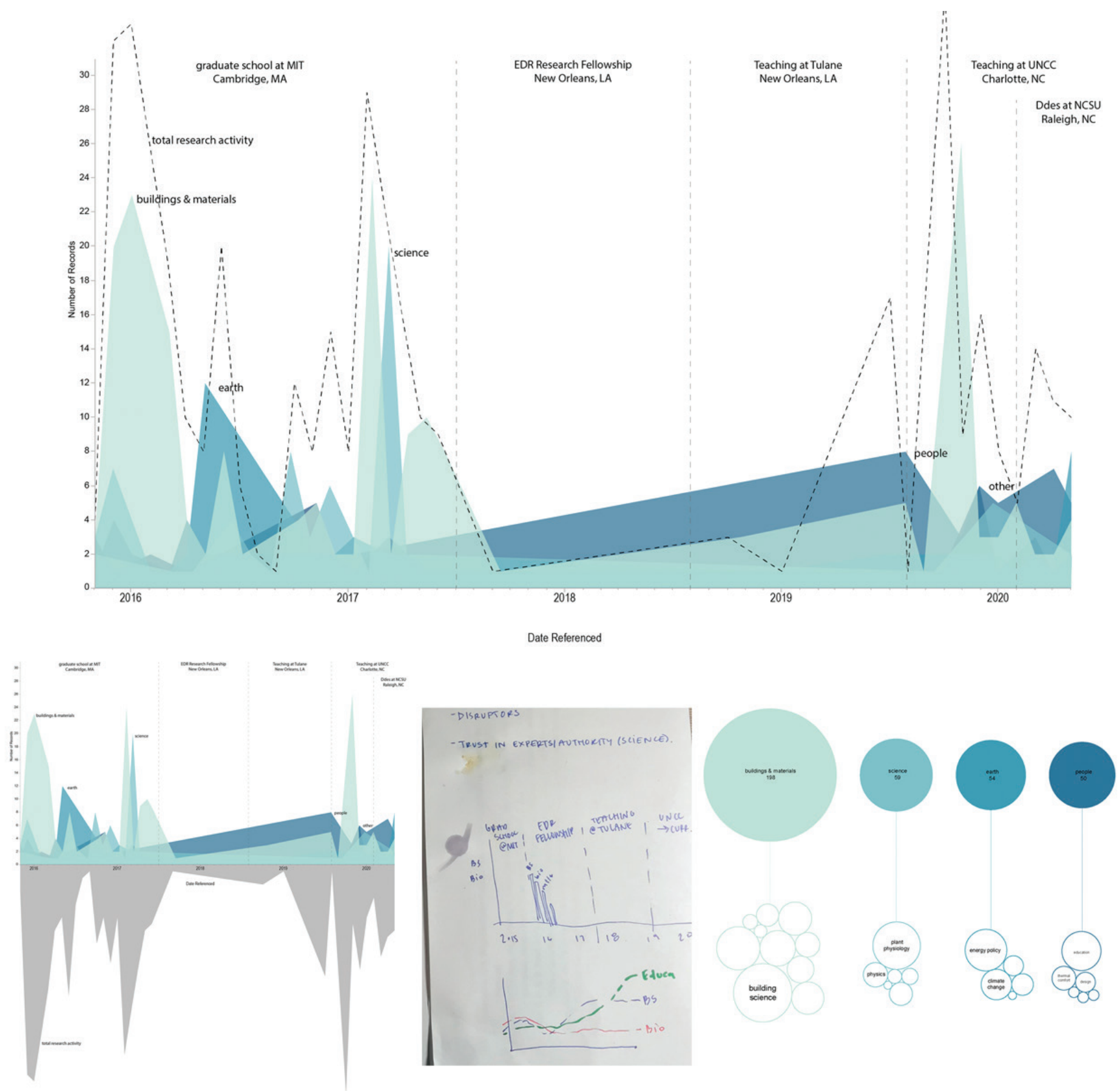

FIGURE 5: Examples of iterative visualizations by Liz McCormick. Top: Final visualization displaying total research activity (dotted line) and specific research topics (colors) over time. Bottom images show structural iterations that play with axis, visual organization and connectivity. Image Credit: Liz McCormick, North Carolina State University.

own thinking, research and learning had evolved throughout the course of the literature assembly.

In the final phase, students overlaid multiple dimensions to their visualizations to afford themselves further opportunities to evaluate patterns 
and gaps in the formulation, operation and analysis of their current research. Subsequently, these could, and sometimes did, provide opportunities for further development of a given line of inquiry, or for the articulation of what could be developed into a contribution of viable knowledge to the discipline. These visualizations were not intended to be comprehensive, but rather to provide a snapshot of the students' research to-date, and acted as an artifact of their process throughout the class. Students then augmented these visualizations by overlaying them with multiple visualizations, or isolating individual pieces of information to examine more closely. The phase acted as a reflective and reflexive tool, and provided an opportunity for more explicit examination of the holes that exist in a given research topic overall. Framing discussions as critical inquiry, students asked questions of each other and themselves as a more explicit activity that transpired as an aspect of sense-making.

Framing arts-based creative research as a means to guide data visualization and as a tool to guide critical inquiry revealed some important opportunities and limitations. Not surprisingly, various levels of intimate knowledge with the content meant that students came to the process of visualization with degrees of conclusions pre-formed in their minds. While the act of critical inquiry was evident in all cases, there was a wide range of growth as a result of the process. One of the issues around the concept of validity that emerged from this process was a tension between the desire to make the visualization "attractive" regardless of whether or not that attractiveness was actually accurate or revealing. But many of the students indicated that the process fundamentally altered the way they viewed their own research and provided pivotal insights into their topic and research conduct. Most notably, the iterative process of visualization contributed to a detachment from the material that encouraged self-criticality and which many indicated was crucial to their own ability to move forward effectively with the research process. Finally, the activity of visualization was "fun" - encouraging intellectual risk-taking and an open-ness to new interpretations of their own work, and the work of others.

Iteration, Technological Inquiry and Play: an Examination of Muriel Cooper's Pedagogy and Practice

A uniform definition of play can be difficult to establish among researchers because of its idiosyncratic and ambiguous nature. Instead, researchers often summarize it with a list of characteristics - freeing, outside the ordinary, 


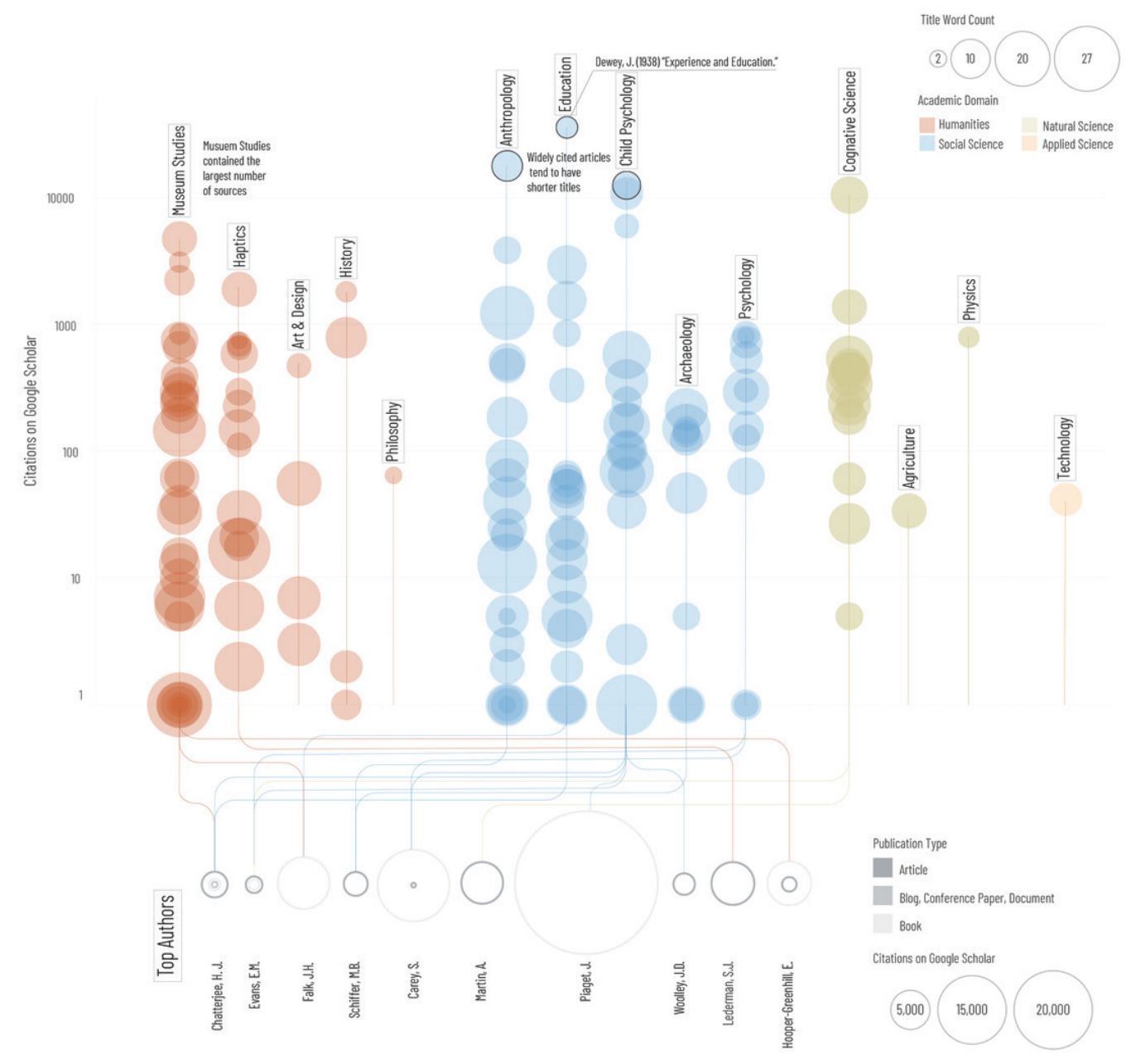

21

Eberle, S. "The Elements of Play, Towards a Philosophy

and a Definition of Play." American Journal of Play, 6(2) (2014): pgs. 214-233.
FIGURE 6: Final visualization looking at authors, fields of research, language and publication type. By Jonathan Williams. Image Credit: Jonathan Williams, North Carolina State University.

uncertain, guided by rules, and fun. ${ }^{21}$ To address the second question of how play itself might encourage open-ness and risk-taking, we can glean insight from the career of Muriel Cooper. A practitioner that pushed the boundaries of digital technologies, Cooper probed the possibilities of new technologies, yet remained focused on ensuring that the human experience with these technologies would be positive. In her many years at the Massachusetts Institute of Technology, she formed and sustained a highly iterative, open-ended and playful research environment, demonstrating how these are essential qualities of innovative practice. She was a key player in the establishment of the MIT Media Lab, which is still valued as a highly creative and experimental space by people working across a diverse array of disciplines. 


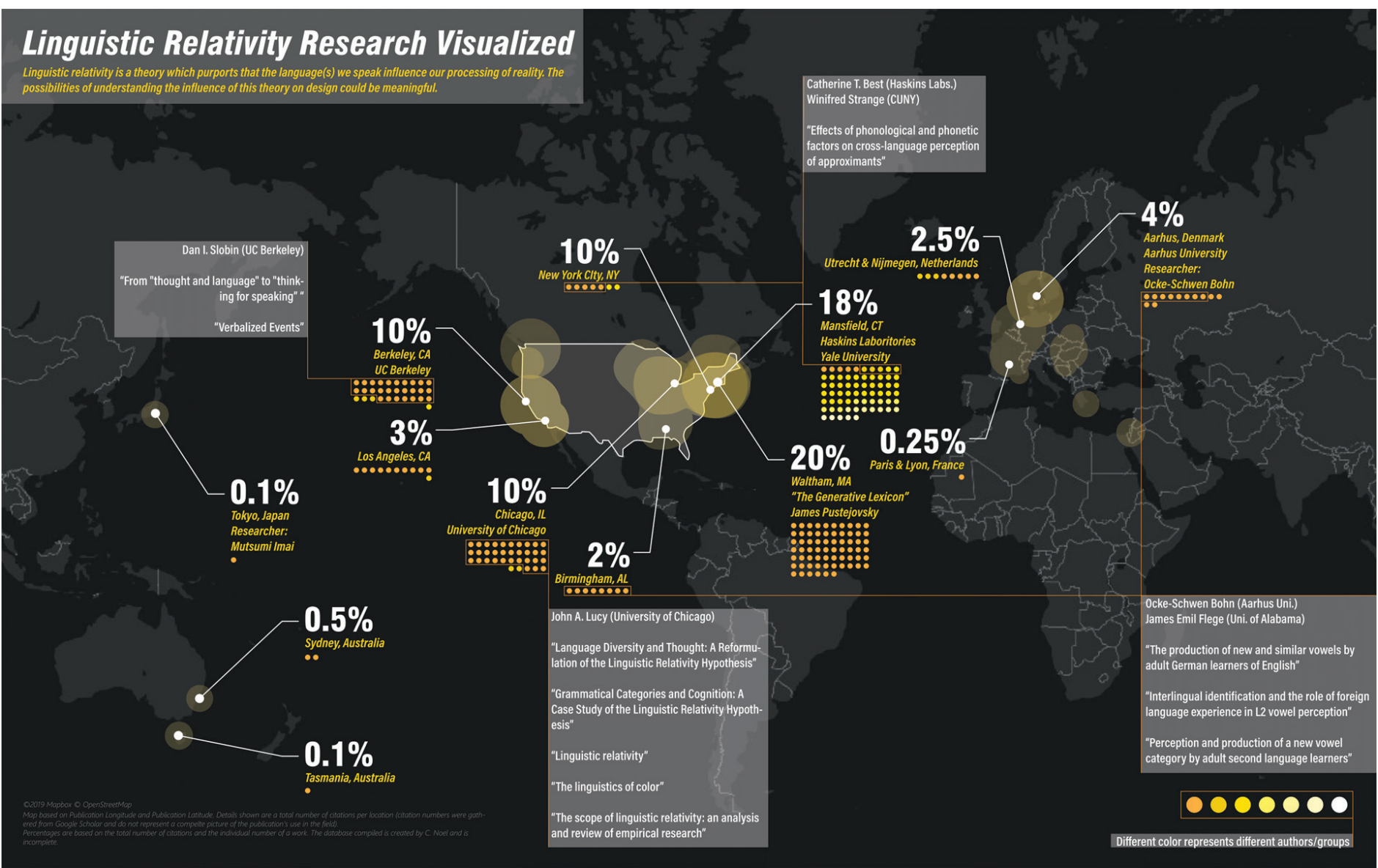

22

Reinfurt, D. A New Program for Graphic Design. Los Angeles, CA, USA: Inventory Press 2019.

23

Massachusetts Institute of Technology. Muriel: A Symposium. 8 January 2018. Online. Available at: youtu.be/a8pMOgLFnPM.

(Accessed 3 April 2021).
FIGURE 7: Final visualization looking at publication and authors geographic origin along with common keywords by Chris Noel. Image Credit: Chris Noel, North Carolina State University.

In the 1970's, Cooper created an informal "research and development" unit within the Miт Press to challenge the standard format for printing and production techniques. In 1973 the "research and development" unit became a course, entitled Message and Means, in collaboration with photographer Ron MacNeil (who was quite technically savvy). Cooper was convinced that a workshop environment, where teaching happens in a feedback loop with hands-on production and design, would produce the type of experimental work that would fully explore the rules of complex systems related to technology, media and visual language. ${ }^{22}$

Cooper instigated an environment in Message and Means where the inherent uncertainty in creative production was positioned as a key component of research and practice. According to MacNeil, she "asked students, who normally spend all day thinking abstractly, to connect their imaginations to their hands in creative exploration." ${ }^{23}$ Many of the students were drawn into the 


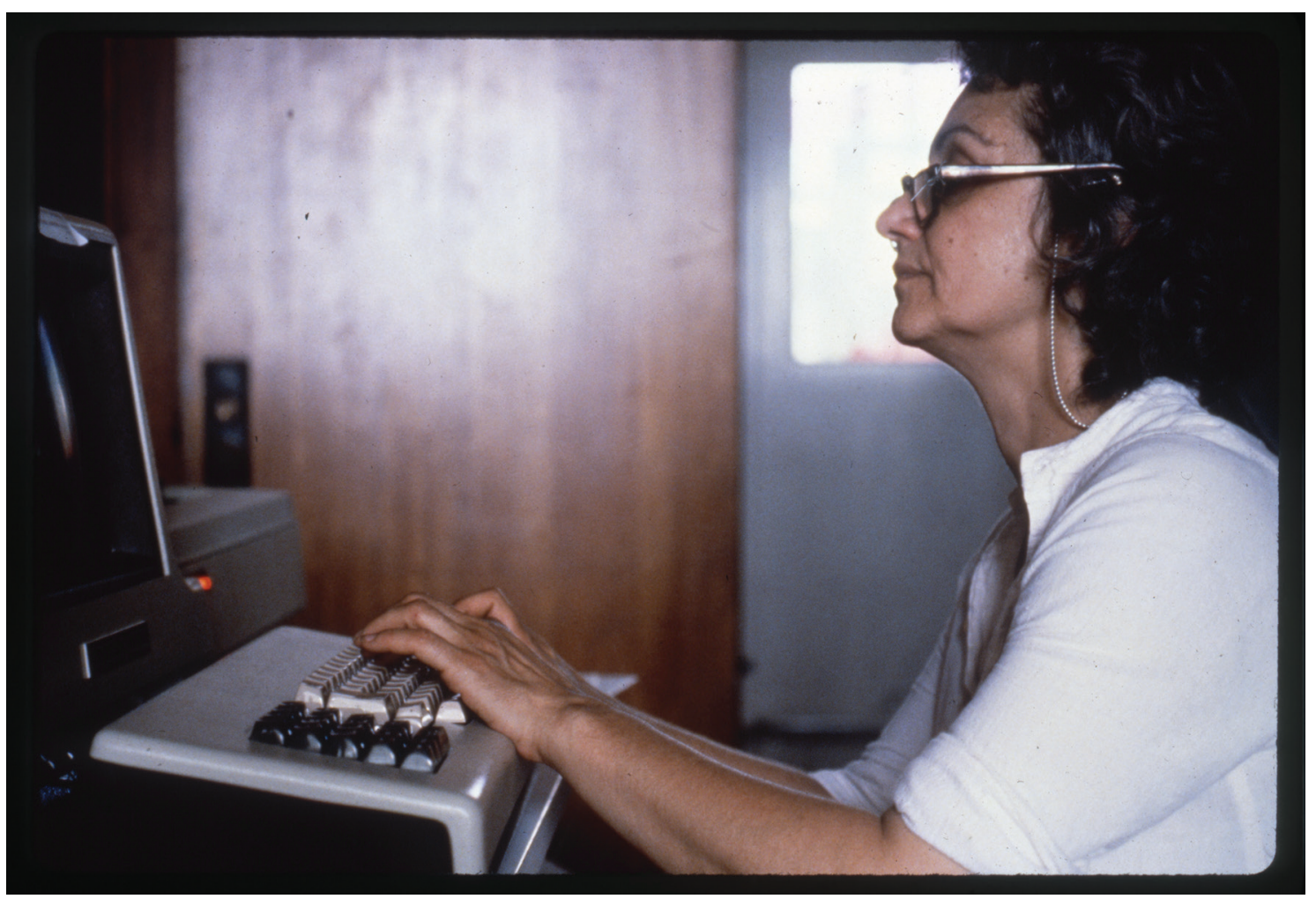

${ }^{\text {a }}$ Press type consisted of individual letterforms, usually appearing in black or white, of a particular typeface set in a specific point size that, when rubbed with a pencil tip, would transfer onto a variety of surfaces. Dialectic's readers who were in design school between the late 1960 and the early 1990 s may remember it well.

\section{4.}

25

Reinfurt, D. A New Program for Graphic Design. Los Angeles, CA, USA: Inventory Press 2019.

\section{6}

Morley, M. “Looking Back on Muriel Cooper's Visions of the

Future." Eye on Design (blog). 5 Dec 2019. Online. Available at: eyeondesign.aiga.org/murielcoopers-visions-of-a-future/. (Accessed 3 April 2021).

Ibid.
FI GURE 8: Muriel Cooper at Computer, 1978. Visible Language Workshop archive, MIT Art, Culture and Technology Program Special Collections. Image Credit: Massachusetts Institute of Technology. sheet of paper was then passed at least four times through the press, and the ink color was changed with each run. The end product was known as a "onenight print." Through the balance of structure and open-ness, and aided by the constraint of time, the project exposed students quickly and enthusiastically to an otherwise intimidating technology. ${ }^{25}$

After the initial uncertainty surrounding process and tools, the students became intimately familiar with the means of production, and found themselves constantly exploring new ways to use the technology at hand, producing playful typographic prints with the large offset printer. This environment of play would continue and influence the way that Cooper went on to think about teaching environments, as well as the new medium of computers. ${ }^{26}$ 
Reinfurt, D. \& Wiesenberger, R. Muriel Cooper. Cambridge, MA, USA: The MIT Press (2017), pg xiii. 28 Ibid., 11.

29

Reinfurt \& Wiesenberger, Muriel Cooper, 30-34.

30

Eco, U. The Open Work. Cambridge, MA, USA: Harvard University Press, 1989.
The Visible Language Workshop (VLW) proceeded from the course Messages and Means, and expanded the scope and technological opportunities, exploring the future of digital interactions. Lisa Strausfeld, a student of Cooper's, wrote, “The physical space of the VLW felt both safe and exploratory, a bit like a family den or a preschool playpen with a couple million dollars' worth of toys." ${ }^{27}$ In addition to the playful process, the expectation at the VLW was open-ownership, and shared authorship which ensured a continuity and evolution of the work. As Cooper herself stated, "I have a profound disdain for answers." For her, there were only challenges - and solutions were more like mistakes. ${ }^{28}$ Research progressed along a timeline as new students built on previous students' research, continuing and also expanding their intentions through new lenses. For example, the research project on digital interfaces entitled Information Landscapes gave rise to a series of sub-projects such as, "Typography in Space," "Financial Viewpoints," "GeoSpace," "Interactive Calendar," "Network Multiviews," "Filtering the News," and "Personalized Galaxies of Information," which were created, built upon and re-created for over a decade at the VLw by such students as David Small, Suguru Ishizaki and Lisa Strausfeld. ${ }^{29}$ This approach to design - where the work itself is not finished and is meant to be continually in a state of evolution and change, is sometimes referred to as an open work. Italian semiotician Umberto Eco highlighted this type of work in his book, The Open Work. Eco's notion of “openness" is described as having defined constraints and latent characteristics that guarantee the work will always be seen as a whole rather than conglomerations of random components. Open works provide rules or structural vitality, and are characterized by the invitation to make the piece in collaboration with the author. ${ }^{30}$ Open works initiate a structured, co-creative relationship wherein designers can think about everyone who might interact with the project as potential collaborators, creating an atmosphere where uncertainty, freedom and the characteristics of play allow ideas to grow.

Muriel Cooper built a pedagogy that allowed play to flourish. She invited productive curiosity and experimentation and embedded coauthorship and ownership into her classroom and practice. Her students literally tore down walls to protest an awkward room arrangement when they initially formed the Visible Language Workshop, demonstrating the characteristics she cultivated inside and outside of the classroom. In creative cooperation, she and her students developed new design vocabularies and 


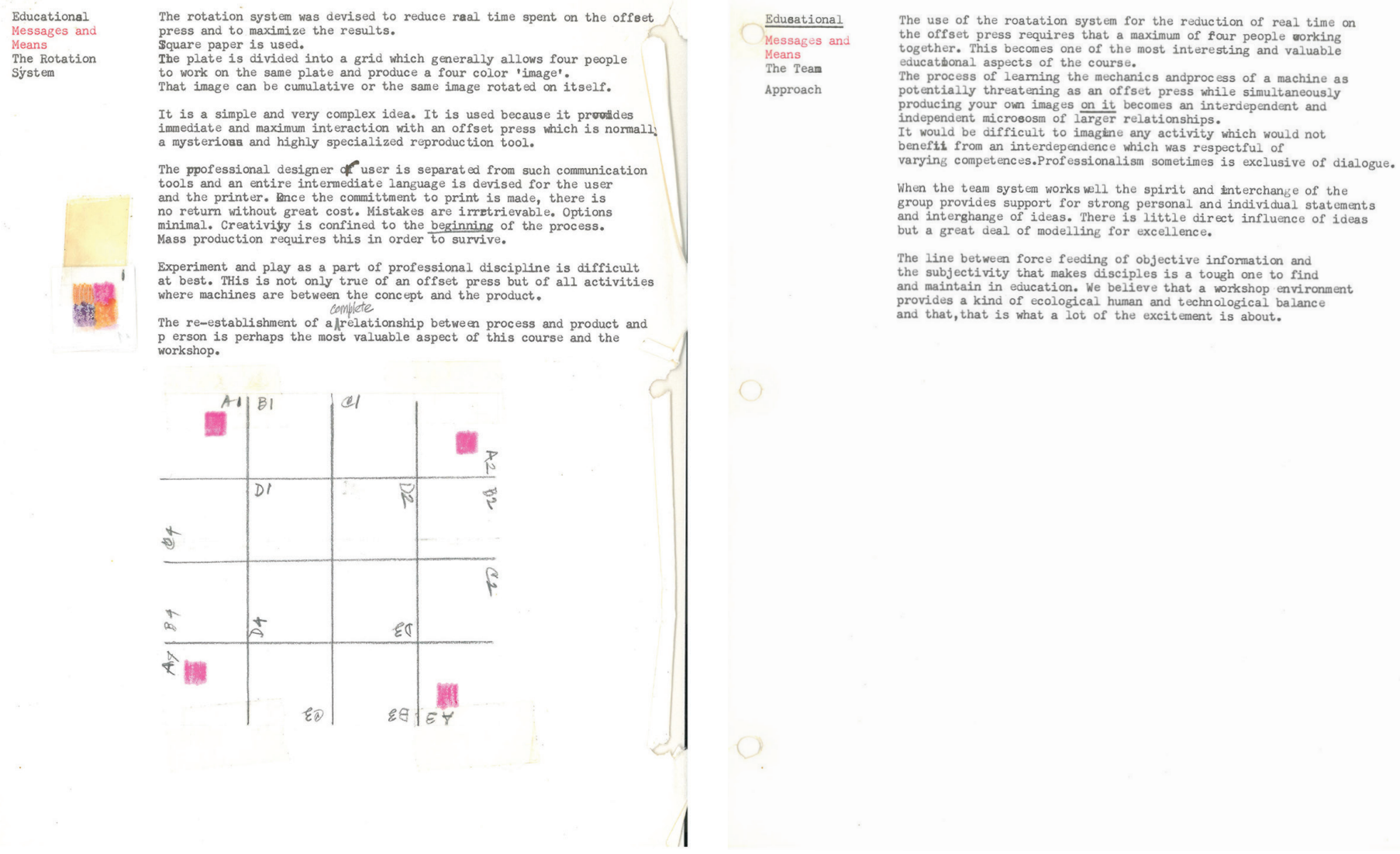

The rotation system was devised to reduce raal time spent on the offset

The plate is divided into a grid which generally allows four people That image can be cumulative or the same image rotated on itself.

ith is a sinple and very complex idea. It is used becase it proc a mysterioss and highly specialized reproduction tool.

The ppofessional designer of user is separated from such communication (activities machines are between the concept and the product.

he re-establishment of a frelationship between process and product and perhaps the most valuable aspect of this course and the
The use or the roatation system for the reduction of real time on

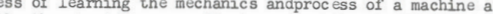
potentially threatening as an orfset press while simultaneousiy independent micrososm of arger relationships. from an interdependence which was respectful of When the team system works well the spirit and interchange of the perong personal and lndividual statements deal of modelling for excellenc.

between force feeding of objective information and maint in in education. We believe is a taus a The

FIGURE 9-10: Muriel Cooper, "The Rotation System” (left) and The Team Approach (right), Messages and Means Course Folder, Visible Language Workshop archive, MIT Art, Culture and Technology Program Special Collections. Image Credit: Massachusetts Institute of Technology.

31

Muriel Cooper, Unpublished interview with Ellen Lupton, May 7, 1994.

\section{Building Empathy and Criticality: Investigating the Work of Rafael \\ Lazano-Hemmer and the Technology of Participation}

A look at the artist Rafael Lazano-Hemmer's work offers potential answers to the third question regarding how creative research can offer insight and deeper empathy in a participatory process. Similar to Cooper's aim to utilize play to raise questions, the artist Rafael Lazano-Hemmer's work creates conditions for people to explore, engage with and reflect on fundamental social issues related to technology and connectivity in an initially playful way. A Canadian-Mexican artist with a degree in physical chemistry, Lazano-Hemmer's work employs technology as a tool for examining the human condition. At the intersection 
32

Lazano-Hemmer, R. "Underscan: Relational Architecture 11." Artist's website. https://www. lozano-hemmer.com/under_scan.php (Accessed 20 April 2021).

\section{3}

Bourriaud, N. Relational Aesthetics. Dijon, France: Les presses du reel (1998): pg.16.

34

bitforms gallery. "Rafael LazanoHemmer: Confirmation Bias," news release, 2018. Available at: https://bitforms.art/exhibition/ rafael-lozano-hemmer-confirmation-bias/\#press-container (Accessed 26 July 2021). of art, design, science and technology, his work also explores issues of space, place, and humanity, performing at intimate and grand scales often simultaneously. Using elements of relational architecture and techno-futurism he illuminates — both physically and metaphorically — what is visible and invisible in our fears, expectations, biases and attitudes. His work tackles concepts of tracking and recording, and integrates technology as a medium by which to engage each other and the world around us, often fundamentally shaping our understanding of it. "Trackers detect your presence and react to your behaviour. Recorders record and keep a memory of your participation." ${ }^{32}$ While not explicitly stating that he is engaged in creative research, there is much that we can learn from the way Lazano-Hemmer sets up, conducts and explains his projects and processes that can contribute to a better understanding of how creative research might be integrated more intentionally in design.

What makes much of Lazano-Hemmer's work particularly resonant is his use of the liminal quality of public space. Nicolas Bourrieaud introduced the power of art to act as a social interstice in his 1965 essay, Relational Aesthetics. Arguing that it "creates free areas, and time spans whose rhythm contrasts with those structuring everyday life, and it encourages an interhuman commerce that differs from the 'communication zones' that are imposed upon us." ${ }^{33}$ Through this unbounding, an audience might be more receptive, honest, and open to new thoughts, positions and ideas by being freed from the normal rhythms of the everyday.

Lozano-Hemmer's reflexive use of technology is also provocative, specifically when utilizing methods like tracking, capturing and visualizing data in order to reveal larger attitudes present in society. Simultaneously, using contemporary media platforms to activate participants in a collaborative project, he also questions its invasiveness and asks the audience to have a similar dialogue. These themes were explored in multiple dimensions in the $2017 \mathrm{ex}-$ hibition Confirmation Bias, and specifically in the piece "Saturation Sampler." As the press release described it, the project used “...AI computer vision to track onlookers and extract the most saturated color palettes from their bodies and clothes...creating a gridded composition from the footage, where viewers catch glimpses of their reflections in the pixelated field." ${ }^{34}$ This use of technology and public space is potentially fruitful for research because it can foreground what happens when people are confronted with the unexpected and the realities of everyday culture in a way that forces an examination and explicit reflection on it. By casting a light on the invisible barriers that we take for 
35

Lazano-Hemmer, R. “Underscan:

Relational Architecture 11."

Artist's website. Available at: https://www. lozano-hemmer.com/under_ scan.php (Accessed 20 April 2021).

36

Menezes, C. "Rafael LozanoHemmer interview: 'An artwork is like a nightclub - only when the public come in do you know if it's going to be a good party'." Studio international. 16 September

2014. Available at: https://www. studiointernational.com/index.php/ rafael-lozano-hemmer-newmedia-art-digital-technologysphere-packing. (Accessed 27 July 2022) granted, and then watching how people respond, he can be seen as experimenting with our thresholds for acceptance of emerging and entrenched cultural norms. Relieved of the expectations of uncovering a singular truth, LazanoHemmer's work also shows us how users or participants could be integrated into the research process in an open-ended way, in order to discover divergent realities of human behavior.

One of his earlier projects, Underscan, demonstrates a number of the strategies outlined above, and offers some unconventional ways to think about empathy and participation in design research. A 2005 interactive video installation set in a number of public squares in the $\mathrm{UK}$, Underscan incorporates some novel strategies for collective participation. "In the work, passers-by are detected by a computerized tracking system, which activates video-portraits projected within their shadow." 35 The pre-recorded video portraits then engage the passer-by by appearing to look directly at them. The video portrait then fades, and remains invisible until triggered by another passer-by. As a participatory tool, this piece engages both the passers-by and the volunteers who made the video portraits individually and collectively in some interesting ways.

The volunteers making the video portraits were given a large amount of latitude in the content and style of their piece, as long as they looked directly at the camera while creating it. Similarly, one video portrait is illuminated by one passer-by at a time. However, the onlookers can view multiple pieces simultaneously_creating a duality and simultaneity between an intimate experience and that of the spectacle of all experiences. As LazanoHemmer himself described it, the volunteers making the portraits “....were completely free to record themselves however they wanted. The only thing we asked of them was to look straight at the camera at one point. I'm looking for artworks that are out of my control. It is people who will in the end complete them, through their interpretation, their views, their memories, their uses.” 36 In addition to the reference to the art movements and artists tackling issues of the gaze between subject and audience, Underscan can also be seen as challenging social, temporal and cultural norms regarding human contact, intimacy, sympathy and even time. By recording the passers-by, the project can examine how different age groups, individuals, pairs or groups respond similarly and differently, or how passers-by engage differently depending on the time of day, or other events around them that are happening simultaneously. And since the project is not chained to a single location, one could see how people engage with it differently at different city scales, or in different parts of the world. 

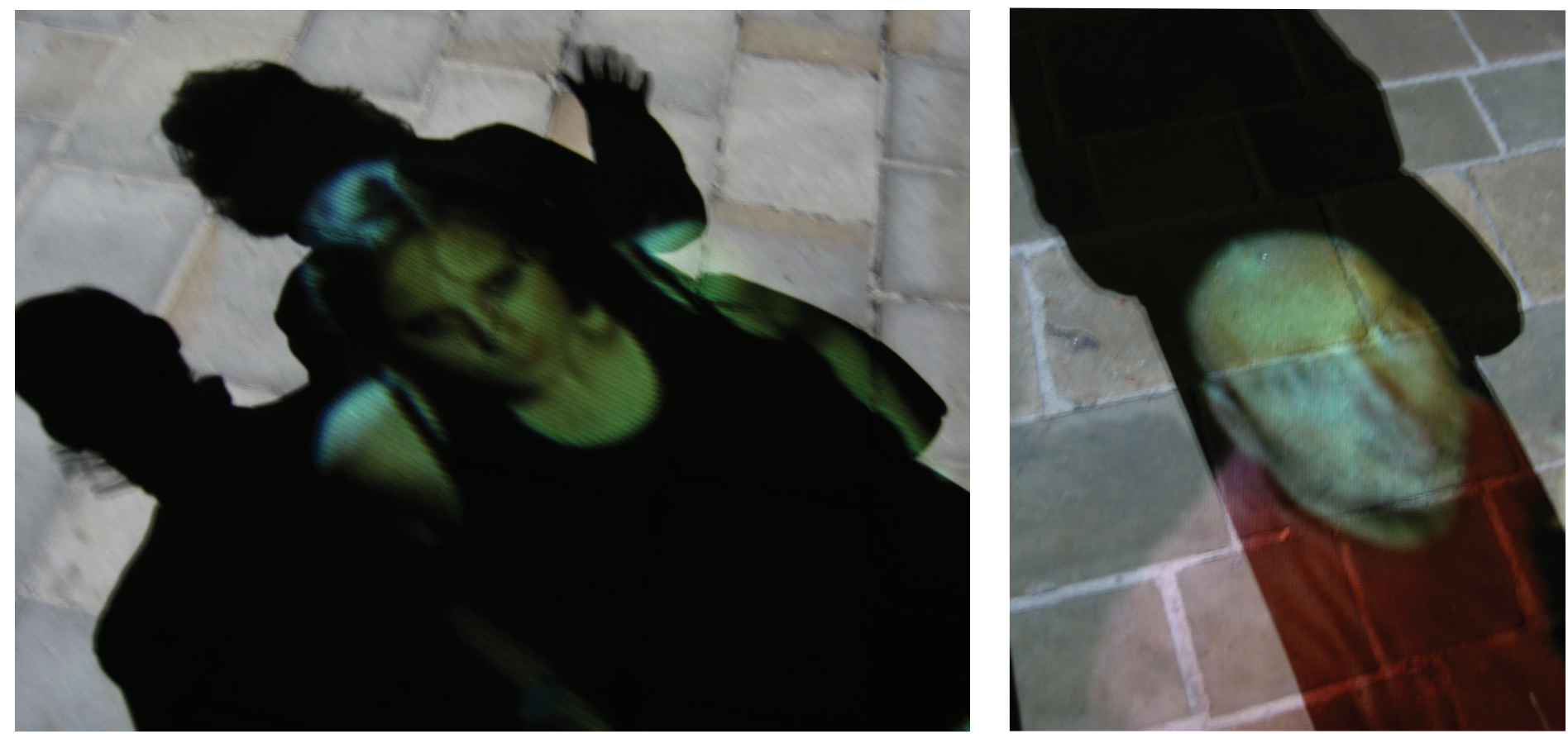

FIGURE 11-12: Stills from user interaction with Underscan. Images by Nathan Livings, Image Credit: Flickr Creative Commons.

By bringing projects into the public sphere, Lazano-Hemmer often confronts a loss of control within the work - relying on viewers to both activate and stay engaged with it. At a base level, this engagement (or sometimes lack thereof) indicates another potential level of findings about what resonates with whom and why. Lazano-Hemmer attributes the levels of willingness to engage with the work, and especially how that seemingly contradicts contemporary society's reflection of the spectacle, to a number of reasons. The first is the fact that we live in a rule-based society, especially when it comes to art. People are conditioned not to touch it, and so interactive art contradicts a basic "rule" about art that most people have come to understand and embody. The second is that many people don't see public space as neutral, and don't want to "go along with a culture of surveillance, even if they know that it is

37

Ranzenbacher, H. "Metaphors of Participation." Takeover who's doing the art of tomorrow.

ARS Electronica 2001. Vienna: Springer (2001): pg. 242. inevitable." ${ }^{37}$ Two strategies that Lazano-Hemmer applies to counter these tendencies - taking turns and taking averages — are of particular consequence. "Taking turns is the most common, and [with]in it interaction is restricted to one or two people who have control of the installation while others are passive. Taking averages is the strategy used in game shows or several variants of interactive cinema where there are sensors whose signals are averaged and then statistically directed at a few possible courses of action." 38 Taking turns

Ibid. allows for idiosyncrasies, and to determine what one or two people might "do" 
with a work - to ascertain the individuality of their responses to it, and allow others to see and learn from these as well. Taking averages-which is arguably what much design research aims to do-removes this individuality and reduces the number of choices to a far lower number, limiting possibilities by democratizing the experience.

What we learn most centrally from artists like Lazano-Hemmer focuses on the alignment between the project setup, or design, and the expectations for interaction that results from the project's placement in spaces that can act as social interstices - public squares, exhibit spaces, or galleries. By placing participants at the center of the work and relinquishing control, he foregrounds a greater empathy for how they might engage and understand it. This can lead directly to more authentic outcomes for a project and its participants, and might offer new ways to engage in a participatory and co-design process.

\section{Conclusion}

In addition to Helen Kara's dimensions of creative research outlined in the introduction, a number of qualities emerge from an examination of the three case studies presented in this piece.

As seen in the first case study, arts-based creative research can be used to engender criticality and risk-taking if seen as an iterative process rather than a finished product. Embedding reflection, discourse and opportunities for reflexivity are also central to re-framing design research from the discovery of a singular and fixed truth, towards an open-ended and evolving process.

Scrutinizing Muriel Cooper's research processes revealed how creative research can succeed in educational contexts when the qualities of play are present, open-authorship is facilitated, and exploration of both new technologies and processes are granted. In Cooper's classrooms, rules and systems were put in place to guide various types of research inquiries, but were essentially there to be investigated and/or rewritten. Authorship was shared as each student continued to further develop the research of past students. This also produced new understandings about approaches and methods as projects expanded in scope and depth across successive iterations. Using the characteristics of play within the walls of the VLW was a key reason that creativity and collaboration flourished there.

Finally, Rafael Lazano-Hemmer's work demonstrates novel ways to generate empathy with and between participants in design and other creative 
processes as a means to generate new forms of content and knowledge. This case study also provides an interesting way to think about the control that is necessary or desired to effectively frame and structure given types of design research approaches, and to be open to unintended outcomes as a central aspect of the design research process.

The following principles for creative research in design begin to emerge:

- Embracing ambiguity and open-ended results: create conditions that are both structured and unstructured, and allow for informed ambiguity.

- Utilizing Play: play encourages tinkering, experimenting and intellectual risk-taking, and can provide low-stakes contexts within which new ideas can emerge.

- Activating the Social Interstice: creative activity is used as a tool to form temporary or long-lasting communities and is cultivated and sustained by separation from the everyday.

- Centralizing Iteration and Contextual Awareness: embedding iteration and shifting contexts can reveal a fuller spectrum of participation and attitudes about the content and the delivery.

- Employing digital tools and technologies: these technologies can provide much-needed constraints, or allow for more uninhibited experimentation - depending on how they are planned for and used - that elicit forms of play and creative output.

- Transparency and Authorship: building transparency into creative production builds trust into the tools of mediation, which creates shared understandings and knowledge between designers and participants.

As the field of design moves to define itself as an independent domain of knowledge, new methods for research and practice will similarly evolve. It has become more common to see both educators and practitioners using creative research methods to shift from the hegemony of the user-centered mindset into one that accommodates creative, critical and productive capacities. In light of this, we end by considering the next steps that could be undertaken to advance creative research in terms of how we might clearly integrate these types of research methods and conditions into design pedagogy and practice 
in ways that are openly arranged as well as more rigidly structured, generative and systematic, and that involve both data gathering and data generating.

Perhaps most importantly, we are advocating for approaches that utilize creative research in a structured and systematic way to help designers and their collaborators engage in decision-making processes that foster authentic empathy, embrace contradictions, challenge the biases that inherently skew our own sense-making, and have fun along the way.

\section{References}

Bourriaud, N. Relational Aesthetics. Dijon, France: Les presses du réel, 1998. Brown, S. L., \& Vaughan, C.C. Play: How It Shapes the Brain, Opens the Imagination, and Invigorates the Soul. New York, NY, USA: Avery, 2010. Buchanan, R. "Wicked Problems in Design Thinking." In The Idea of Design. Edited by R. Buchanan and V. Margolin, pgs 3-20. Cambridge, MA, USA, 1996.

Cross, N. "Designerly Ways of Knowing: Design Discipline versus Design Science.” Design Issues, 17.3 (Summer, 2001), pp. 49-55. Cambridge, MA, USA: The MIT Press.

Eberle, S. “The Elements of Play, Towards a Philosophy and a Definition of Play." American Journal of Play, 6(2) (2014).

Eco, U. The Open Work. Cambridge, MA, USA: Harvard University Press, 1989.

Frayling, C. "Research in Art \& Design” in Royal College of Art Research Papers, 1.1 (1993/4). London, UK: Royal College of Art.

Friedman, M.S., ed. Graphic Design in America: a Visual Language History. Minneapolis, MN, USA: Walker Art Center, 1989.

Frieling, R. \& Letourneaus, F., eds. Rafael Lazano-Hemmer: Unstable Presence. San Francisco, CA, USA: San Francisco Museum of Art, 2020.

Gray, P. “Definitions of Play.” Scholarpedia, Encyclopedia, Online. Available at: http://www.scholarpedia.org/article/Definitions_of_Play (Accessed 20 April 2021).

Gray, P. Free to learn: Why unleashing the instinct to play will make our children happier, more self-reliant, and better prepared for life. New York, NY, USA: Basic Books, 2013. 
Hartnett, J.P. “Paper Trail of a Digital Pioneer.” Eye Magazine, 2018, Online. Available at: www.eyemagazine.com/review/article/paper-trail-of-a-digital-pioneer. (Accessed 3 April 2021).

Kara, H. Creative Research Methods in the Social Sciences, A Practical Guide. Bristol, UK: Policy Press, 2015.

Lazano-Hemmer, R. “Underscan: Relational Architecture 11.” Artist's website. nd. https://www.lozano-hemmer.com/under_scan.php (Accessed 20 April 2021).

Loos, T. “Rafael Lozano-Hemmer Is a Crowd Pleaser. He's Also Obsessed With Death.” The New York Times, 26 October, 2018. Online. Available at: https://www.nytimes.com/2018/10/26/arts/design/rafael-lozano-hemmer-hirshhorn.html (Accessed 20 April 2021).

Manzini, E. \& Coad, R. Design, When Everybody Designs: An Introduction to Design for Social Innovation. Cambridge, MA, USA: The MIT Press, 2015.

Menezes, C. "Rafael Lozano-Hemmer interview: 'An artwork is like a nightclub-only when the public come in do you know if it's going to be a good party'." Studio international, 16 September 2014. Online. Available at: https://www.studiointernational.com/index.php/rafael-lozano-hemmer-new-media-art-digital-technology-sphere-packing (Accessed 23 April 2021).

Massachusetts Institute of Technology. Muriel: A Symposium. 8 January 2018. Online. Available at: youtu.be/a8pMogLFnPM. (Accessed 3 April 2021).

Morley, M. “Looking Back on Muriel Cooper's Visions of the Future.” Eye on Design (blog). 5 Dec 2019. Online. Available at: eyeondesign.aiga.org/ muriel-coopers-visions-of-a-future/. (Accessed 3 April 2021).

Reinfurt, D. \& Wiesenberger, R. Muriel Cooper. Cambridge, MA, USA: The MIT Press, 2017.

Paul, R. \& Elder, L. The Miniature Guide to Critical Thinking Concepts and Tools. Washington, DC, USA: Rowman \& Littlefield, 2020.

Pirinen, A. "The barriers and enablers of co-design for services." International Journal of Design, 10(3) (2016): pgs. 27-42.

Poggenpohl, S. “Time for Change: Building a Design Discipline.” In Design Integrations: Research and Collaboration. Edited by S. Poggenpohl and K. Sato, pgs 3-22. Bristol, UK: Intellect Ltd, 2009. 
Ratto, M. “OPEn DESIgn Now.” Open Design Now, Online. Available at: opendesignnow.org/index.php/article/critical-making-matt-ratto/. (Accessed 3 April 2021).

Razenbacher, H. “Metaphors of Participation.” Takeover - who's doing the art of tomorrow. ARS Electronica 2001, Vienna, Austria: Springer, 2001: pgs: $240-246$.

Sanders, Elizabeth B.-N, and Pieter Jan Stappers. Convivial Toolbox: Generative Research for the Front End of Design. Amsterdam: BIS Publishers, 2018.

Simon, H. The Sciences of the Artificial, Third Edition. Cambridge, MA, USA: The MIT Press, 1970.

Simonsen, J. et al. Situated Design Methods. Cambridge, MA, USA: The MIT Press, 2014.

Spiro, M. Anthropological Other or Burmese Brother? Studies in Cultural Analysis. Transaction Publishers, 1991.

Stariha, M. “From Play to Innovation.” Stanford D.school, Stanford D.school, 9 Oct. 2019, Available at: dschool.stanford.edu/classes/from-play-to-innovation. (Accessed 3 April 2021).

Smyth, Michael. "The radical design movement, More essential history for Speculative Design" SpeculativeEdu (blog). Available at: https://speculativeedu.eu/the-radical-design-movement/ (Accessed 26 July 2021).

University of Minnesota. “The Practice of Play with Dr. Stuart Brown: Taking Charge of Your Health \& Wellbeing", University of Minnesota, 2016, Online. Available at: www.takingcharge.csh.umn.edu/practice-play-drstuart-brown. (Accessed 10 April 2021).

Wiesenberger, R. “Muriel Cooper.” The MIT Press (blog). 28 March 2018. Available at: mitpress.mit.edu/blog/muriel-cooper. (Accessed 10 April 2021).

\section{Biography}

Tania Allen is a designer, educator and researcher based in Raleigh, North Carolina. She teaches courses related to design research methods, mapping as a critical research tool, and visual communication at North Carolina State University. She has a BA in history from Washington University in St. Louis, a Post-Baccalaureate in Visual Communication from the School of the Art 
Institute of Chicago and an MGD from North Carolina State University. In her professional practice, she works with social change organizations to help visually communicate their strategy and vision and to use visualization tools to identify and articulate their work. tlallenz@ncsu.edu

Brooke Chosnyak is a designer, educator and collaborator currently living in Portland, Maine. She teaches graphic design courses as an adjunct professor at Maine College of Art and Northeastern University in Boston. She has an MGD from North Carolina State University and a BFA from Rochester Institute of Technology. In the course of her career Brooke has been a curious traveler, studio collective founder, tool maker, typographer, form maker, and instigator. She believes that design is a catalyst for creativity re-imagining the world we want to live in now and in the future.b.chornyak@northeastern.edu 